\title{
4
}

\section{ST. GALLEN MANAGEMENT MODEL}

\section{Systemic-constructionist approach to workspace organisations and management}

\author{
Annette Kämpf-Dern*
}

\section{Background}

\subsection{History and development}

The St. Gallen Management Model (SGMM) is rooted in the works of Hans Ulrich and Walter Krieg (1972), setting up an integrative management theory (Ulrich, 1984). It was then Ulrich's successor at the University of St. Gallen, Knut Bleicher, who further developed the model over the next decades. Under the name 'Das Konzept Integriertes Management' (The Concept of Integrated Management: Visions - Missions - Programs), the first edition of the book was published in 1991 (Bleicher, 1991). Since then, the concept and the book belong to the management standard literature in German-speaking countries and have been so successful that now -30 years later - its 10 th edition will be published.

The "holistic understanding and integrative treatment of complex management challenges in their unique and differentiated contexts" are what the concept has been all about (RüeggStürm \& Grand, 2019, preface). Instead of isolated sub-disciplines of business administration - e.g. production, marketing, accounting - the St. Gallen approach is a systems-oriented framework for the core tasks of managers and their overall business responsibility.

Regrettably, until recently, the vast majority of economic and social science publications of German-speaking researchers have been in German only, which has greatly hindered the broad dissemination of many ideas and findings. This also applies to the bulk of publications addressing integrative management issues from German-speaking countries and the SGMM. However, a groundbreaking English-language article by Bleicher (1994) found its way into the international research world. It has been and still is cited as a basis of works regarding values, business ethics, and governance, stakeholder management, competitive advantage, innovation management, supply chain management, change management, sustainability management, and performance management. Quoting examples that show the broad applicability are e.g. Hermel and Ramis-Pujol (2003), Schnetzler et al. (2007), Edwards (2010), Edwards (2014), Wieland (2014), Breuer and Lüdeke-Freund (2017), Breuer and Lüdeke-Freund (2019), Hofmann (2019),

\footnotetext{
^kaempf-dern@asbaco.de
} 
Seiler et al. (2020), Velter et al. (2020) - and uncounted further ones that refer to the concept based on the German books or that are already tacit knowledge. This is especially true for the management-level pyramid introduced by Bleicher that distinguishes and explains normative, strategic, and operative management processes (e.g. Breuer \& Lüdeke-Freund, 2015).

Main ideas of the concept of integrative management even found their way into the International Organization for Standardization (ISO) and build the base of the Management System Standards (MSS). MSS are a series of norms for which the most prominent examples are the ISO families 9000 (Quality), 14000 (Environment), or 26000 (Social Responsibility). Even more workspace-related are e.g. the ISO MSS families 20000 (IT), 30400 (HR), 41000 (Facility Management), 45000 (Occupational Health \& Safety), or 55000 (Asset Management). According to ISO, some of the benefits of well-defined management systems are higher efficiency, improved performance, improved protection of people and environment, and especially "increased capability to deliver consistent and improved services and products, thereby increasing value to customers and all other stakeholders" (ISO, 2020). As the MSS follow a common 'High Level Structure', they can form an integrated management system.

\subsection{Purpose}

Bleicher (1994) stated in the abstract:

The growing complexity of the business environment and the increased speed of change in systems, technologies and markets raise the question of whether human beings will be able to control the forces at work in the 1990s. The question is relevant for our ecological and social environment, and also for our institutions. Systems seem to be approaching the limits of their controllability. Thus a change of paradigm in the management of organisations seems to be underway which seeks new approaches to solving management problems in turbulent times.

The purpose of his article and the ideas constituting the foundation of the SGMM were to "discuss how, in view of a rapidly changing environment, the ability of systems for survival and development can be ensured and enhanced" (Bleicher, 1994, p. 136).

The SGMM as a systemic-constructionist approach to integrative management mainly supports a holistic description about and thus reflection on complex organisations, their environments, stakeholders, value generation, processes, management, and the interplay of all parts. Based on this, and enabling a collaborative exchange of perspectives, purposeful development can be initiated and implemented. As a result, instead of solely optimising isolated cause-andeffect relations, a larger and better result will be achieved. (SGMM, 2020a)

The SGMM does not give any specific advice on how to do things. As a framework it rather supports modelling an applied or intended business concept with its fundamental procedures in order to generate the intended output. It is important to note that normative and strategic as well as operational and dynamic aspects are considered. The result, the specific model, is a simplified representation of the value creation processes, functions, and interactions. These help create customer value, secure competitive advantage, and generate revenue (Doleski, 2015).

Such a model facilitates a holistic description, analysis, and further development, especially if - as the SGMM suggests - all relevant environments and expectations (political and legal, economic, socio-cultural, technological, and ecological) are included. Including them makes complexity transparent, which is a prerequisite to managing it. An integrated model alongside 
the dimensions of the SGMM thus "ensures that all factors critical to success are considered in full, with clearly defined, structured components" (Doleski, 2015, p. 5).

A good and visualised description of the value-creating elements and their interplay furthermore enables a collaborative reflection, design, and development of the organisation-specific management practices. Due to "the multifaceted nature of management and its manifold prerequisites” (Rüegg-Stürm \& Grand, 2019, pos. 470 ff.), enabling collaboration is another success factor for responsibly dealing with complexity as the numerous interrelated and dynamic topics require various specialists and generalists. Those usually speak in different disciplinary languages, as do the multitude of further stakeholders to be considered. A mutual terminology and understanding of organisational, process, and management aspects significantly facilitates communication between and collaboration of all these actors.

\subsection{Essentials of the model}

The SGMM is a system-oriented management reference framework that addresses the constant design and development of relationships between the following:

- An organisation (enterprise, public, governmental, or pluralistic organisation, NPO/NGO, or parts of it)

- Its specific, interacting environment (according to Rüegg-Stürm \& Grand, 2019, pos. 409, "the space of possibilities and expectations specifically relevant to an organisation")

- The resulting value creation ${ }^{1}$ as management focus.

In the system-oriented view, any organisation is seen as a complex system that creates specific value in a specific environment. As a system, the organisation is an independent entity that "delimits itself from an environment and consists of diverse elements" (Erk, 2016, according to Rüegg-Stürm \& Grand, 2019, pos. 590) (see also Chapter 3 on systems theory). Depending on the view, the organisation is a social, an economic, a technical, a legal, and a human system at the same time. It includes respective elements such as actions/decisions/relationships, resources/ prices/incentives, rights/obligations/regulations, or skills/knowledge/emotions (to name only a few). Those elements interact in certain patterns which can - because of their complex relationships and interdependencies within and to its environment/context - not be fully understood. They can therefore not be predicted but only influenced by 'structuring forces' and through different 'development modes'.

Accordingly, the SGMM consists of the following elements, here named 'model categories' (Rüegg-Stürm \& Grand, 2019, pos. 679ff.) that concern the basic task and design fields of management practice (see Figure 4.1):

1 Environmental Spheres

2 Stakeholders

3 Interaction Issues

4 Processes

5 Structuring Forces

6 Development Modes

Categories 1-3 relate predominantly to the social, economic, and ecological 'outside' of the organisation, while categories 4-6 are the inside view. 


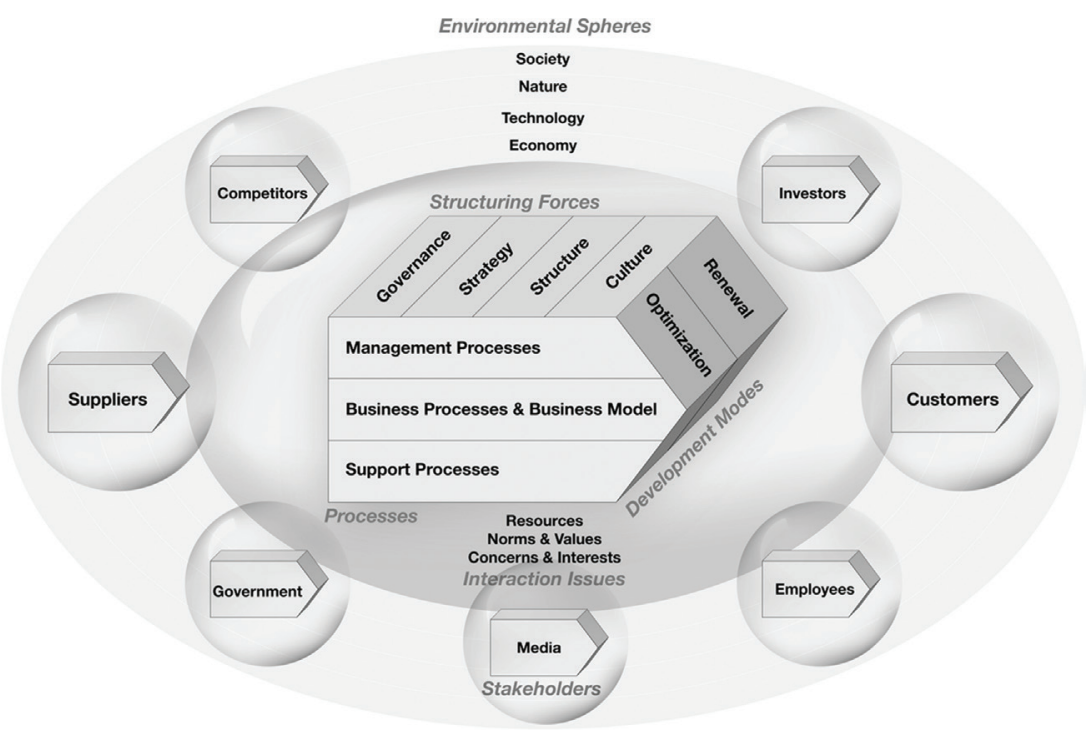

Figure 4.1 The New St. Gallen Management Model (Rüegg-Stürm \& Grand, 2019)

1 'Environmental Spheres' are the relevant contexts of the organisation, the key fields of reference for organisational value creation, with which the organisation is in constant interaction. Societal circumstances are the most comprehensive, but nature, technology, and economy and their relevant changes need to be watched closely and analysed as well regarding status, changes, and trends.

While in the past it was often assumed that an organisation can hardly influence its environment, more and more examples (e.g. Apple, Facebook, Google) show that organisations and their relevant environmental spheres are 'co-evolutionary'. This reflective interaction needs to be considered by management. ${ }^{3}$

2 'Stakeholders' are individuals, communities, or organisations affected by and/or influencing organisations. The purpose of any organisation is value creation for at least some of its stakeholders. According to a term coined by Ulrich et al. (1984), 'management as a social function' replaces leadership responsible only to the owner. Bleicher (1994, p. 138) titles it "From Ownership Management to Stakeholder Management" and thus recognised an important change early on. ${ }^{4}$

As stakeholders' needs, interests, and preferences - a bundle of objectives instead of a straightforward goal hierarchy - are often very diverse and even conflicting, the perceived value creation for stakeholder groups differs considerably, and management normatively needs to define guidelines and methods for prioritisation.

3 'Interaction Issues' are the relevant points and topics of communication between an organisation and its stakeholders. At first glance, discussions are primarily about resources/tradeable goods and their allocation, but often the really important issues are values and norms, concerns, and interests - 'thematic points of reference' - that need clarification and adjustment.

In the first version of the SGMM, instead of norms and values being part of 'interaction issues', those were referred to in the 'Management Philosophy' as the 'Integrating Power'. 
Management philosophy is about the thinking and behaviour of a company's executives. Those are influenced by the executives' basic attitudes, convictions and values which stem from ethical or religious convictions or previous experiences. Bleicher (1994) therefore saw the greatest challenge of adapting an organisation to a dynamic environment in balancing a reassuring management philosophy against openness to innovation.

4 Different kinds of 'Processes', ${ }^{5}$ their functions, and how they are related are at the heart of the SGMM (and what many know best regarding the SGMM). A specific organisation is characterised by its specific 'system of processes' with processes being the organisation's routine procedures that shape every day's work. Organisational success fundamentally depends on owning and using effective and efficient processes - of all kinds and on all levels.

The model differentiates 'business processes', 'support processes' and 'management processes' (Figure 4.2).

The business processes are in the centre, as those are the processes that are directly connected with the market/customers/clients and the organisational value creation. Therefore, they are often called the 'primary activities' (Porter, 1985) or 'core' processes. These include customer acquisition and retention, branding, production and delivery, and innovation/ R\&D (see also Chapter 11 on branding theory).

The support processes (often called 'secondary' processes) enable the business processes, as only with the support of (internal or external) services, e.g. procurement, HR, legal advice) and infrastructure (e.g. ICT, real estate and facilities), business processes can be performed effectively, efficiently, and thus value creating (see also Chapter 18 on service management theory).

Value creation commonly demands division of labour and specialisation, which requires communication, cooperation, and coordination in order to achieve defined objectives. Business and support processes thus need management processes, analysing, designing, aligning, and organising, steering, controlling, and developing the organisation and its processes. ${ }^{6}$ Because of their very different roles, management processes are divided into 'normative', 'strategic', and 'operational' management levels. The normative level gives orientation; the strategic level identifies potential and develops the organisation, its people,

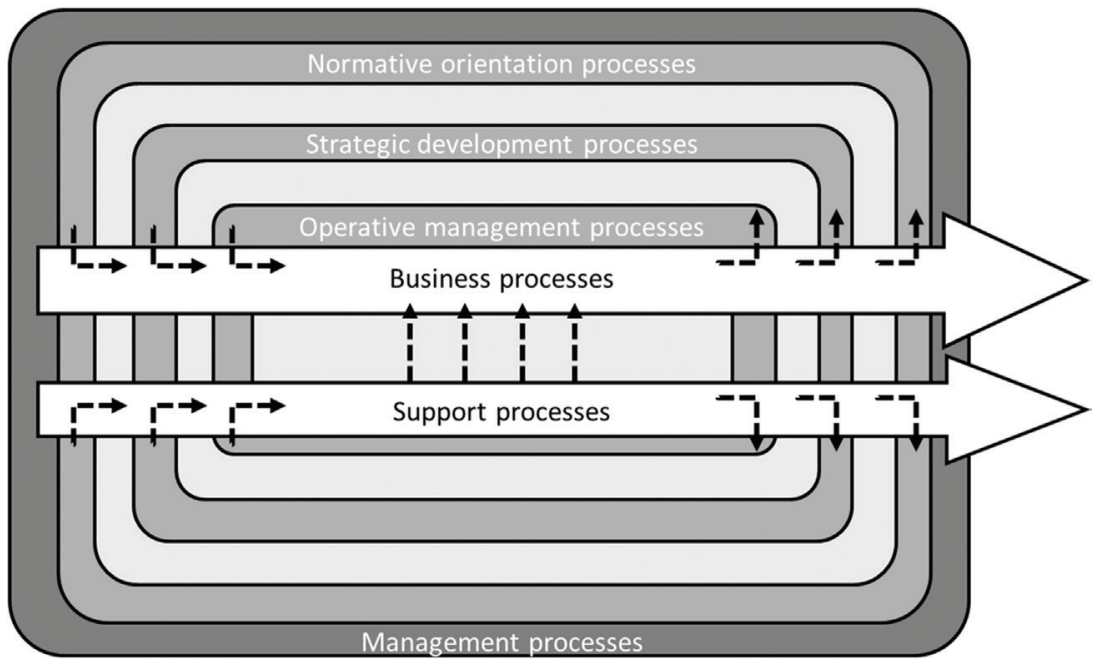

Figure 4.2 Process categories and architecture (Rüegg-Stürm, 2005, p. 54) 


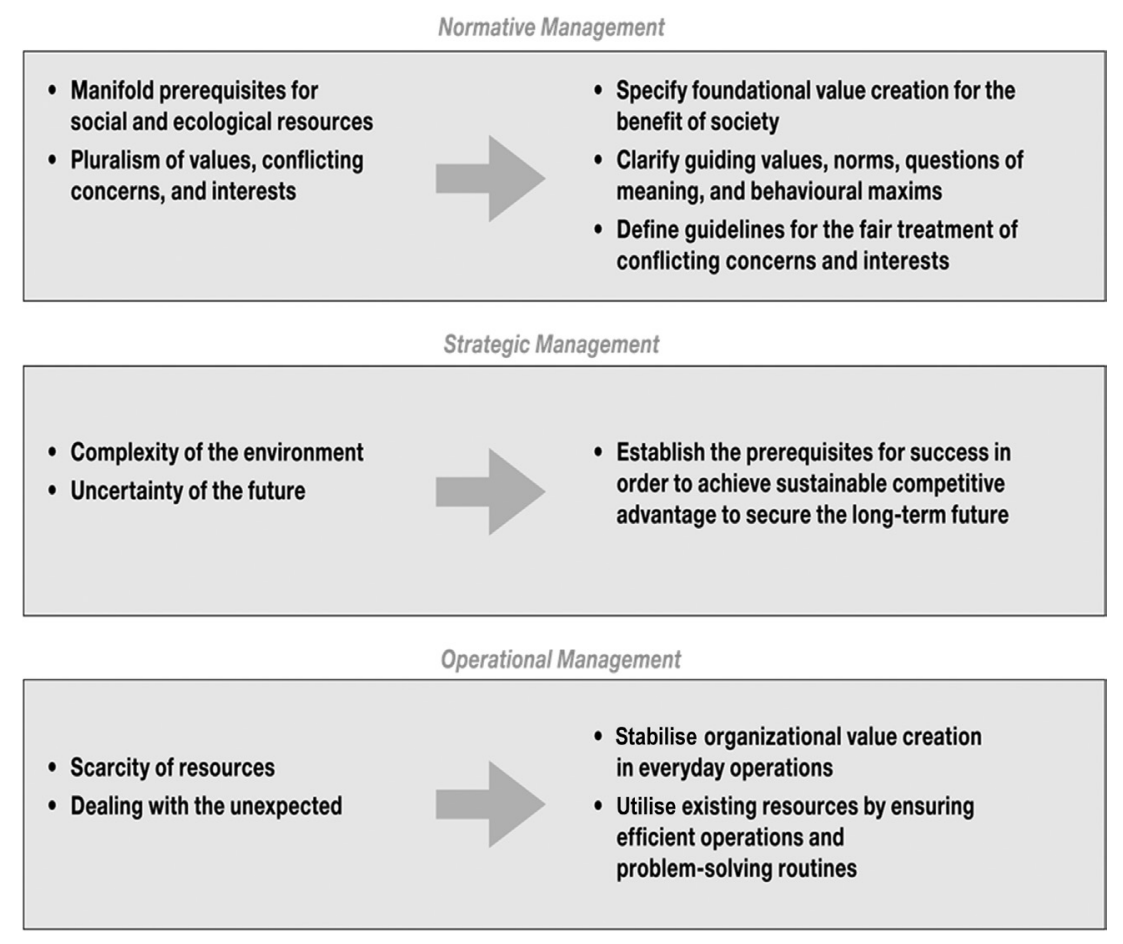

Figure 4.3 Process categories and architecture (Rüegg-Stürm \& Grand, 2019, p. 64)

and processes; the operative level manages the individual people and processes on a daily basis, including their finance and quality issues. (Figure 4.3)

- "Normative management addresses general business objectives and defines the constitutive values, principles, standards and rules that shape an organisation's identity and establish the creative framework for business actions" (Doleski, 2015, p. 10). It thus indicates the direction. All organisations' activities and members' behaviour need to be justified and legitimised in that way - to both internal and external stakeholders.

- Strategic management's task is to identify ways and develop and steer the organisation to achieve strategic advantage and the overall goals while adhering to set norms, values, and rules. This is to be achieved through projects and initiatives regarding the fundamental shape and focus of organisational structures and management systems, and through staff's problem-solving capabilities and behaviour shaped by learning and corporate culture (Bleicher, 2003, p. 162).

- Operational management's domains are practical implementation of normative and strategic tasks and individual people management. Operational management implements the actions required by the two superordinate dimensions into operational processes of performance, finances, and information (Doleski, 2015, p. 10).

Process design, alignment, and integration are accordingly the essential and creative work of managers to achieve a coherent, value-generating organisation (Rüegg-Stürm \& Grand, 2019, pos. 703f.). 
Table 4.1 Four terms as described by Rüegg-Stürm and Grand (2019)

\begin{tabular}{ll}
\hline Term/Concept & Description (Rüegg-Stürm \& Grand, 2019, pos. 695 ff.) \\
\hline Governance & $\begin{array}{r}\text { [S] erves to define and structure an organisation's purpose, identity, vision, mission, and } \\
\text { normative orientation with basic regulations, each defining the roles, rights, and } \\
\text { duties of managers. }\end{array}$ \\
Strategy & {$[$ A]rticulates an organisation's competitive positioning, differentiation, and long-term } \\
development direction. & [E]mbodies the ... organisational configuration. \\
Structure & {$[$ E]xpresses an organisation's basic behavioural assumptions, beliefs, rules, values, norms, } \\
and attitudes.
\end{tabular}

5 'Structuring Forces' are supposed to shape the organisation in a way that its elements function as coherently towards intended value creation as possible, meaning that the desired impacts of processes are achieved. 'Governance', 'Strategy', 'Structure', and 'Culture' each are exerting orienting, structuring, and motivating forces (Table 4.1). ${ }^{7}$

Yet, they cannot guarantee that results are reached as intended, due to the individual configuration as well as the complex interactions and dependencies of the various social-system elements. This is why management - defining and establishing the structuring forces - is called a 'practice' (see Chapter 7 on Strategy-as-Practice), an 'art' or 'craft' rather than a science: Depending on the context and the configuration, the same measures can have wildly different results. Therefore, whether the effects match the expectations often is a question of experience, observations, and reflections.

Also to be considered is the circular connection between processes and structuring forces. While structuring forces develop and form all processes, processes and/or their results, on the other hand, can influence and lead to change of structuring forces - e.g. process optimisations initiate changes of organisational structure.

6 'Development Modes' "describe basic patterns of how organisations can evolve in a dynamic environment” (Rüegg-Stürm \& Grand, 2019, pos. 717f.). Development can reach from incremental steps at few issues ('optimisation') to radical, disruptive changes at fundamental characteristics of the organisation ('renewal'). What is best in which situation depends on many parameters, but it always needs to be balanced carefully to ensure that the organisation moves into the desired direction while not descending into chaos.

Moreover, changes should not only be looked at on a factual level. Factual changes regularly impact social relationships and emotions. Therefore, balancing organisational development always implies to consider both aspects.

As of today, the development to the SGMM and its areas can be described as follows:

[T] he first-generation SGMM by Hans Ulrich and Walter Krieg (1972) was characterised by a systems-theory and entrepreneurial orientation. The second generation (Bleicher, 1991) deepened the explicit differentiation of management into operative, strategic, and normative aspects. The third generation (Rüegg-Stürm, 2002) illustrated how organisational value creation for a dynamic environment needs to be understood as a complex interplay of value-creation processes. The fourth generation (Rüegg-Stürm \& 
Grand, 2017) emphasizes the communicative and reflective function of management, and accordingly reconceives management as a reflective design practice.

(SGMM, 2020b)

\section{Applicability to workplace studies}

Groups/units/entities providing healthy and productive workspaces and workplaces can be regarded as complex organisations, within a larger organisation or as a stand-alone service. The application of the SGMM can help managers of such entities to develop, design, and operate workplace-related core, management, and support processes in order to optimise value generation for their many stakeholders. Workplace studies can apply the SGMM in various ways:

1 As an agreed-upon terminology for important dimensions, characteristics, and terms for workplace organisations and management to get a holistic, integrative representation:

An adequate terminology and structure improve transparency and clarity, communication, and insight. Just as the SGMM specifies the general system theory in relation to organisations that achieve added value through targeted division of labour, the elements and relationships of the SGMM must be specified and concretised in relation to work environments in order to enable and promote communication. This includes typical workspace stakeholders, their goals and objectives, potential strategies and structures for workplace provision, workspace-providing core, support and management processes, and cultural impacts of workspace change as well as development and change options.

Comprehensive and structured descriptions of workspace situations or problems are possible only on the basis of such a specified and agreed-upon terminology. A workspace-related organisational terminology also facilitates the identification and consideration of connections, interfaces, and influencing factors. Moreover, potentially missing or contradicting aspects are easier to locate this way. These advantages are realised even if only a single case is investigated.

\section{To identify workspace-relevant performance metrics.}

With the systematic specification of workspace-relevant stakeholders and their respective interests, norms, and values, researchers can identify the respectively relevant performance metrics. The term 'respectively relevant' is used, as an organisation's interests and values are configuration-specific (e.g. industry-, size-, region-, task-related). Accordingly, it can be assumed that the importance of particular workspace performance metrics varies - corresponding integrated research is yet rare.

3 As a comprehensive base for identifying context-configurational-design patterns and effective performance-enhancing actions/processes.

As each work environment is a unique case with a multitude of parameters to consider in research, the comprehensive SGMM - together with other management research insights - can guide and support the identification of relevant configurational parameters for workspace issues. For those parameters, research can then discover principles as well as patterns and relationships and their correlation with value-enhancing processes. 
For systematic testing and development.

It is expected that research of work environments will develop in a way similar to that of practice and research in medicine: on the one hand, towards a strong specialisation, on the other hand towards the (re)discovery of holistic approaches. For the latter, the SGMM - when concretised for workspace issues - offers an excellent basis to develop and test recommendations, identify general principles, or even establish holistic workspace management theories.

5 As a common ground and shared know-how with other disciplines, here management, work sociology, and work psychology.

An integrated management model facilitates the exchange between workspace researchers, not only in terms of general communication, but also regarding research methodologies, tools, and even insights. Workspace researchers can locate their field of study within its organisational context within the SGMM, and thereby more easily discover potential research fellows, methodologies, and/or insights for their research.

All these applications will support developing and operating the core, support, and management processes of work environment provision and operation. They thereby increase the probability that the intended value generation for the various stakeholders and specific contexts materialise as planned (see also Chapter 12 on value-added management).

As illustrated to this point, and thanks to the possibility of 'zooming-in' to and 'zoomingout' ${ }^{8}$ of the SGMM, the model can be applied to a multitude of questions and areas of the workplace. Following are a few examples from own research. ${ }^{9}$

\subsection{Specified common terminology: management levels, processes, perspectives, and organisational configurations in (corporate) real estate}

Real estate and facilities management are rather young disciplines and have been lacking adequate terminologies for a long time. Central ideas from the SGMM were therefore translated into (corporate) real estate and its management in the works of Kämpf-Dern and Pfnür (2009) and Kämpf-Dern $(2009,2010)$. This applies especially to the dimension 'processes' with its differentiation in management and business processes, and the management levels, explicating normative, strategic, and operative real estate management. Furthermore, the dimensions 'stakeholders' and 'environmental spheres' in real estate were addressed.

Figure 4.4 show parts of these terminological 'definitions' that were necessary as a foundation for further real estate management and workplace studies. According to the St. Gallen management concept, management processes with various functional tasks have been differentiated, yet adapted to the language used in real estate. The normative management level is the real estate investment management level (REIM). The strategic management level regarding real estate portfolios is the real estate portfolio management (REPM), and regarding individual assets the real estate asset management (REAM). The operational management level is the Property Management (PrM) for investment real estate and Operative Real Estate Facility Management (OREFM) for corporates/publics. RE management processes plan, organise, steer, and control RE business respectively RE support processes (here called real estate services $=$ RES) over all RE life cycle phases. Not shown here are further details and translations of existing RE management and services specifications to the SGMM model dimensions. 


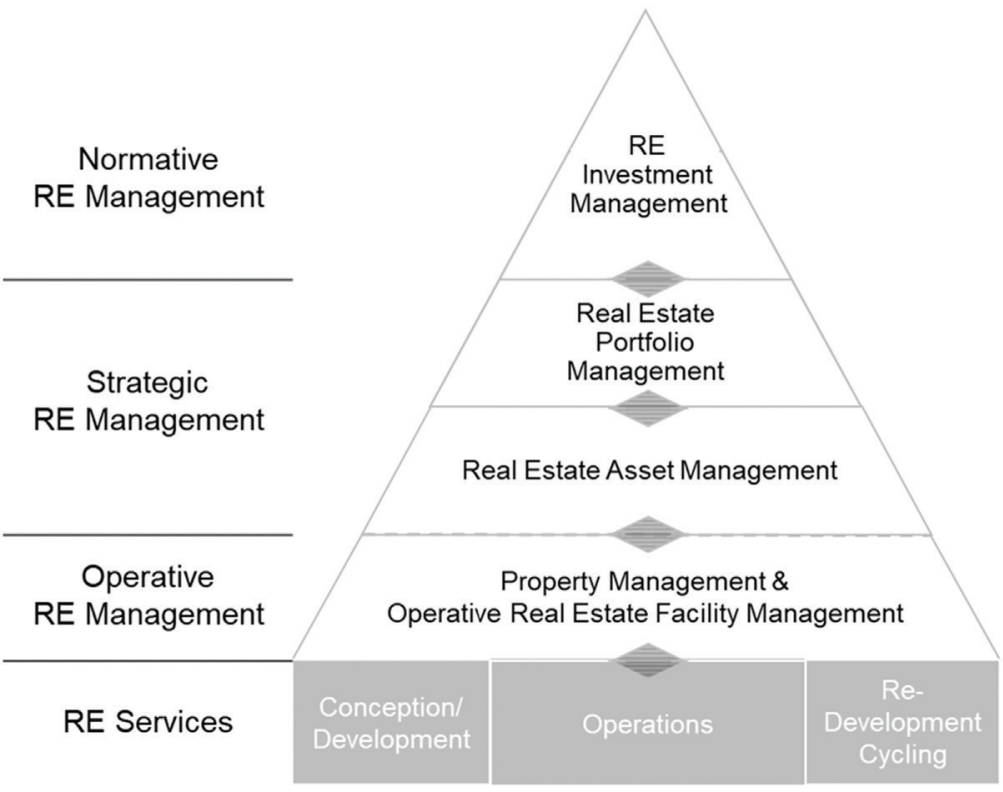

Kämpf-Dern (2010)

Figure 4.4 Real estate management and core processes (translated and adapted based on Kämpf-Dern, 2010)

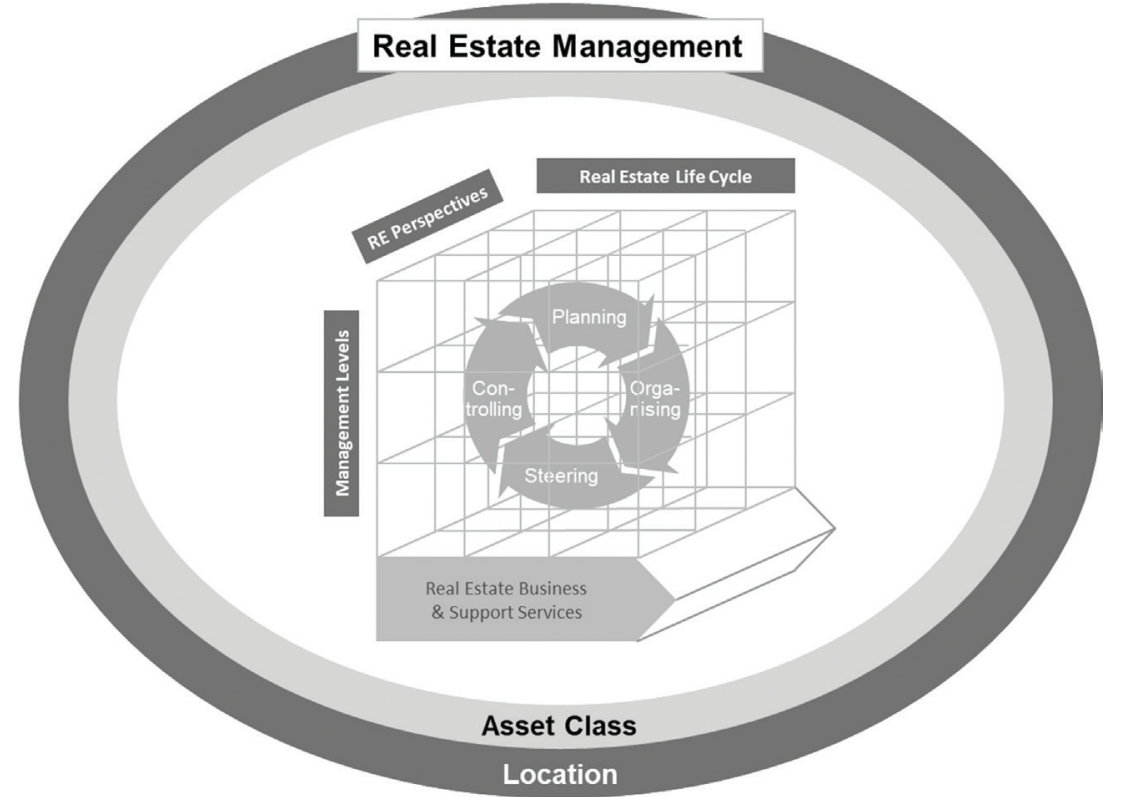

Figure 4.5 Real estate management basic concept (translated and adapted based on Kämpf-Dern \& Pfnür, 2009) 
Figure 4.5 adds further categories: Instead of 'development modes', 'perspectives' (investor, user, producer) were added to the core organisation, representing most relevant stakeholders including their interests and objectives. Directly impacting 'environmental spheres' in real estate are asset classes (e.g. whether the real estate belongs to Office or Logistics) and the location (micro and macro location/region/country).

Based on this comprehensive representation, with the possibility to achieve 'zoom in and out', clarity was brought into the communication of real estate management tasks, and the vast majority of real estate research could be located within this real estate adapted, integrative management concept.

\subsection{Identification of common patterns and working configurations: 'Best Practice? Best Model? Best Fit!'}

Larger companies with a portfolio of sites are faced with the question of how to structure their CREM\&FM activities and the related organisational units. In essence, the overarching problem to be solved is the business model for their infrastructure provision.

The 'CREM-Map', described in the paper 'Best Practice? Best Model? Best Fit!', transfers large parts of the SGMM to the CREM\&FM world (see e.g. Figure 4.6).

Here, the focus was on the alignment of the CREM entity with the corporate entity as well as on the alignment with corporate goals and context (context-system-fit). Furthermore, the research detailed and investigated the CREM-related 'structural forces', here corporate governance, goals strategy, and culture, together with CREM objectives, strategy, and structure. The coherence of structuring forces with CREM processes (inter-system, respectively, intra-system fit) was another area of analysis. The SGMM set the stage for structured interviews with international corporates to identify CREM best practices but - not surprisingly - neither best practices nor best models could be identified. Instead, some 'principles' crystallised, and the configurational 'fit', the alignment between the elements and the management philosophy, proved to be most important for perceived value-generation.

\subsection{Joint reflection on holistic models for value creation: 'Performance-oriented office environments - framework'}

The SGMM as a holistic, interdisciplinary, systems-oriented framework regarding the interactions and interdependencies of organisation and environment including stakeholders, and its

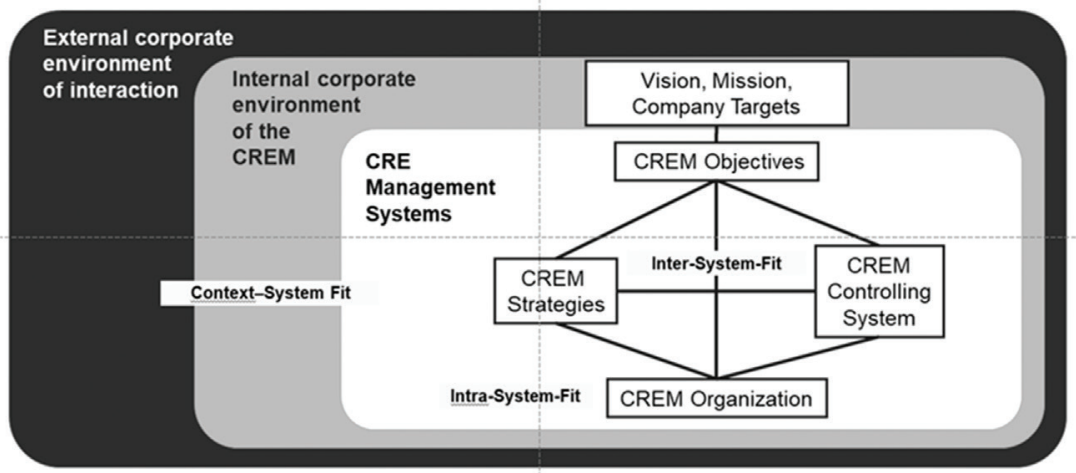

Figure 4.6 The CREM Map (Kämpf-Dern \& Pfnür, 2014, simplified) 
value creation as focus of management, inspired the enhancement of the office ecology model to a 'performance-oriented office environments framework' (Kämpf-Dern \& Konkol, 2017). The framework supports joint reflections and development of coherent and therefore performing office environments and how to include change aspects ('development modes').

Stakeholders are at the same time in the centre of the model ('People') and actors ('Management', 'User Representatives', other support functions) who design and develop their workplaces. 'Management Processes' as well as 'Structuring Forces' make up the 'Leadership/Management Subsystem'. Business Processes are represented by 'Work processes/activities'. They are supposed to be enabled and supported by the surrounding 'Physical Workspace', 'Workspace Technology', and 'Workspace Services' which are explained in detail in this conceptual paper, including a broad workspace aspects literature review. The purpose is to give an overview of the up-to-date insights and principles of workspace design and implementation. As being stated in the SGMM, 'Development Modes' and 'Corporate Culture', the social aspects of management are just as important as strategy and structure of a business. Only if the change process is designed and implemented as professionally as the workspace design, the intended performance metrics (outcomes) will be reached. This is also shown and addressed in this piece of work (Figure 4.7).

\subsection{Identifying context-configurational-design patterns and effective performance-enhancing actions/processes}

Current research work covers a very different approach to context-configurational-design pattern identification regarding workplace. It attempts to acquire and analyse big data through a gamified survey app named SIM-OFFICE. A system approach allows for investigation not of isolated causeand-effect-structures, but of distinct categories with assumed strong relationships. The categories are a combination of soft and hard factors related to workspace. The research looks for configurational clusters of personality, task, values, and workplace parameters, which then can be further researched. These clusters are deducted from the performance-oriented office ecology model: personality, job design, leadership, physical workspace, workspace technology, and workspace services.

The assumption to be checked is that there are configurational patters of personality traits and job design with specific preference structures regarding the latter four categorical elements that - when fulfilled - result in higher performance metrics.

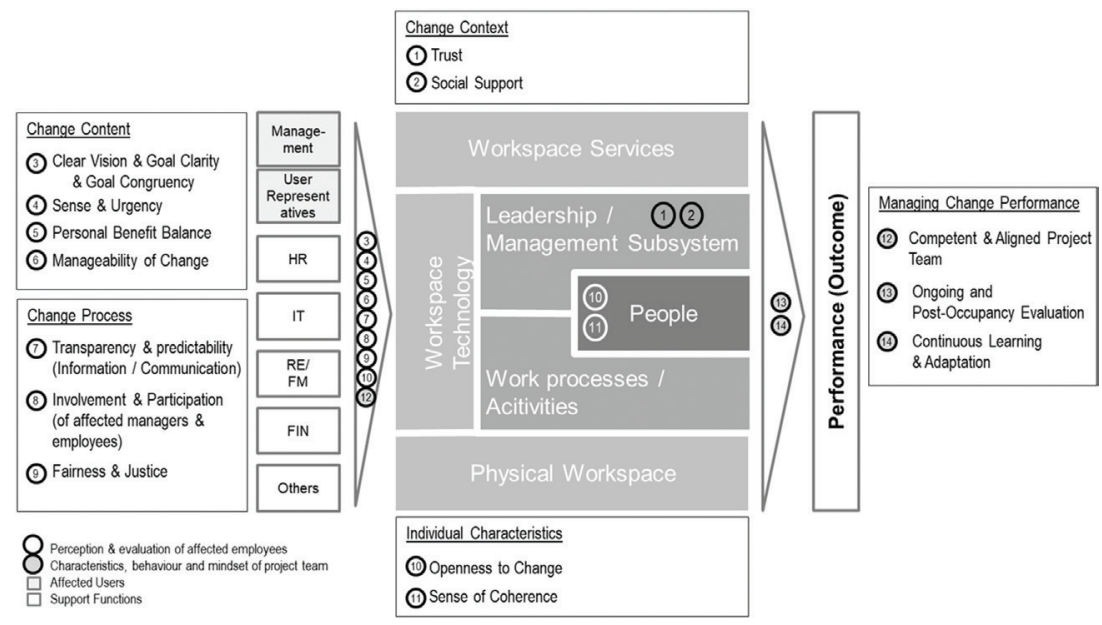

Figure 4.7 Performance-oriented office ecology model (Kämpf-Dern \& Konkol, 2017) 


\subsection{Sharing and collaborating with other disciplines}

The named research examples were and are possible only with transdisciplinary knowledge and respective collaboration with researchers that come from management, real estate, architecture and engineering, ICT, and sociology/psychology. According to Bleicher (1994, p. 138), "Stakeholder management necessitates a higher frequency of border-crossing relationships to other systems which have so far been kept separate . . . [a] cross-border co-operation in networks". This can be confirmed when applying the SGMM as an integrated management concept to workspace issues. It can also be seen in the positive development of an association like the TWR Network that enables and promotes such border-crossing co-operations.

\section{Methodology/research approach}

The challenge of research related to complex - integrated and interdisciplinary - socio-economic institutions (e.g. CRE\&FM departments) or process systems (e.g. workplace provision, operation, and management) lies in the almost infinite number of configurations that are possible due to the multitude of dimensions and parameters which characterise them (for the consequences see e.g. Straub, 2013).

Especially social science researchers are facing this challenge. Common research approaches are case studies (e.g. Yin, 2017) and mixed-method approaches (e.g. Creswell, 2014) that combine socio-empirical qualitative and quantitative methods, e.g. documents and interviews (e.g. Witzel, 2000), and qualitative data analysis methods (e.g. Flick, 2013), combined with mixed qualitative and quantitative surveys.

The grounded theory methodology (Glaser \& Strauss, 1967; Strauss \& Corbin, 1990; Dougherty, 2002) can be useful to construct hypotheses and theories and generate ideas and concepts in areas where little is known yet, like in the field of workspace management. This methodological approach has been used for investigating real estate asset management as a professional service (Kämpf-Dern, 2010). While the results are not statistically significant, they build a good foundation for further research.

However, purely quantitative research methods can rarely be used for integrative management questions. Those methods - up to now - either could cover only a limited number of relationships, and thus not adequately reflect the complex configurations under investigation, or would need an enormous number of data points and very large sample sizes. The latter conditions are often neither available nor affordable.

Management research, therefore, often works in stages. Following an overall understanding of certain patterns through grounded theory and mixed methods, the research then 'zooms-in' to more specific parts and questions. These can then be investigated more quantitatively under 'ceteris-paribus-conditions'.

However, the situation could change with the new technical possibilities of data collection and analysis (keywords: Artificial Intelligence and Big Data). These may further open up the field for complex and system-oriented research - good prospects for integrative management research.

\section{Limitations}

Systemic approaches to a complex field like workplace management require a lot of pre-work and a broad set of methods, and then they provide 'only' complicated, context-dependent 
answers. In any case, they are "excessively descriptive" (Geissler \& Krys, 2013, p. 33) and need huge samples before being able to identify patterns that lead to fact-based insights and solid recommendations. Collecting these samples in turn requires large funds, take some time, and are less specific. For that reason, companies hire consultants to solve their individual and specific problems with conventional wisdom and knowledge from consultants' experience, rather than commissioning management research projects that advance general insights and promote the discipline but do not instantly 'pay back'.

Moreover, due to the context dependency and interaction, generalisations will always be difficult to be made in this field of system-analysis - within the organisation and regarding environmental spheres as well as regarding stakeholders. Easy-to-understand solutions like 'best practices' or 'best models' can therefore not be made, which makes these kinds of approaches less attractive. However, pattern recognition is possible and very effective. A workspace-specified SGMM can provide a good framework for this as starting point.

\section{Theory relevance to practice}

The advantage and differentiation force of the SGMM is that it sees an organisation as a whole, within its context, and including the social interactions. It considers not only isolated parts of the organisation or the individual unit but also its environment, including stakeholders outside the organisation and their reflexive interdependencies and interactions. Depending on the problems and questions to be solved, the model allows to 'zoom' in and out, changing the focus and nevertheless keeping its integrated, holistic, and interdisciplinary view - extremely practical in a globalised, connected, and fast-moving world.

Obstacles of the model have been named under Limitations: It is excessively comprehensive, which requires - in addition to a lot of managerial general knowledge to understand and follow up on the various aspects - a vast amount of documentation and specifications. However, this is necessary because complex questions will not be solved with simple answers (Geissler \& Krys, 2013), even though anybody, practitioners as well as researchers, would prefer a simple over a systemic approach.

Despite the limitations, which seem to make the application of the SGMM to workplace research less attractive for practitioners, the SGMM has had much greater impact in the industry than in science. Virtually thousands of business managers have been educated with this model and apply its essentials in their daily work. For workplace managers who are mostly not trained in business, getting to know the model can therefore also be very fruitful.

Furthermore, the following workspace management research gaps could be filled through applying the SGMM and would be interesting for practice:

- Review and further development of a management terminology specified for work environments

- Interests, norms, and values of workspace stakeholder groups in different environments, resulting management philosophies, and value generation metrics

- Organisational set-up of workspace entities in different environments (company size, industry, culture) including competence requirements

- Workspace strategy development processes and alignment with corporate strategy and corporate culture

- Integration of workspace topics in corporate sustainability and innovation management processes 
- $\quad$ Process maps of workspace core, support, and management processes

- Use of new technologies and digitalisation to increase the quality and efficiency of workspace core processes (e.g. workspace design, facility service provision)

- Inclusion of broader groups of workspace stakeholders into workspace-related management processes.

Last, but not least, the roots of the model - while going back more than thirty years could hardly be more recent. The 'VUCA'10 environment has reached the workplaces, especially since the outbreak of COVID-19. Accordingly, managing workplace and other organisational infrastructure as if they were solid, reliable, and stable is no longer possible. Professional workplace management to master complexity and support organisational value creation through adequate provision and operation of workplaces has become a necessity. Understanding and applying the SGMM in its fourth generation and transferring insights from its general usage to workplace questions offers practitioners great potential. This can be magnified when corporations and researchers cooperate to extend the usage of the SGMM from helping with describing and structuring workplaces to identifying patterns, and thus being able to give fact-based (instead of only experience-based and plausible) recommendations.

\section{Notes}

1 In this work and most settings that require management, 'value-creation' denotes that "an organisation or a network of organisations creates value through division of labor". The outcome of value-creation are "products or services (or effects in general), from which value creation addressees (e.g., customers) can derive a specific benefit” (Rüegg-Stürm \& Grand, 2019, pos. 341-342, 352).

2 According to Erk (2016), dimensions of a system are oneness/entirety, elements/components, environment, connections/relations, complexity, structure, and - in the centre - purposefulness.

3 In the management literature, the reflective dependencies are described under the headlines of 'marketbased' versus 'resource-based' views of the firm. (Porter, 1979; Barney, 1991)

4 Until the end of the last century, the predominant and accepted belief was that companies should be guided solely by owner/shareholder interests. Only in the course of the sustainability and CSR considerations of the last twenty years the position grew that value creation is higher if more stakeholder groups agree with the actions of a company and if as many interests as possible are aligned - also for those with a primarily monetary interest in the organisation (e.g. Hillman \& Keim, 2001; Gimpel et al., 2019).

5 "Processes are sequential activity patterns that are systematically interrelated and characterizable in terms of their factual and temporal logic" (Rüegg-Stürm \& Grand, 2019).

6 'Management' "primarily means mastering complexity" (Rüegg-Stürm, 2005) "when designing, steering, and developing purpose-oriented social institutions" (Ulrich, 1984). It "always concerns organisational value creation" (Rüegg-Stürm \& Grand, 2019, pos. 327).

7 'Structuring forces' in this text are not to be confused with the concept of Porter's Five Forces (Porter, 2008). While the latter is a framework to analyse the competitive intensity and the environmental attractiveness of an industry in which a business model is or shall be established, the 'structuring forces' of the SGMM are those with which managers can influence - design and develop - processes within the organisation.

8 What it means to 'zoom' in and out, and why this is an important capability for managers, is well explained in Kanter (2011).

9 The international dissemination of the SGMM was severely limited by the focus of teaching and research on the German-speaking regions and the German language. Conversely, there have been very few researchers in the field of workspace management in German-speaking countries. Accordingly, the author is not aware of any further research that would have explicitly applied the SGMM to work environments.

10 VUCA = Volatile, uncertain, complex, ambiguous 


\section{Further reading}

Bleicher, K. (1994). Integrative management in a time of transformation. Long Range Planning, 27(5), 136-144. doi:10.1016/0024-6301(94)90234-8

Kämpf-Dern, A., \& Konkol, J. (2017). Performance-oriented office environments - framework for effective workspace design and the accompanying change processes. Journal of Corporate Real Estate, 19(4), 208-238. doi:10.1108/JCRE-03-2017-0009

Kämpf-Dern, A., \& Pfnür, A. (2014). Best practice, best model, best fit. Journal of Corporate Real Estate, 16(2), 97. doi:10.1108/JCRE-09-2013-0027

Rüegg-Stürm, J. (2005). The New St. Gallen Management Model: Basic Categories of an Approach to Integrated Management. Basingstoke: Palgrave Macmillan.

Rüegg-Stürm, J., \& Grand, S. (2019). Managing in a Complex World. The St. Gallen Management Model. UTB: Stuttgart.

\section{References}

Barney, J. (1991). Firm resources and sustained competitive advantage. Journal of Management, 17(1), 99-120. doi:10.1177\%2F014920639101700108

Bleicher, K. (1991). Das Konzept Integriertes Management. Das St. Galler Management-Konzept. Frankfurt: Campus.

Bleicher, K. (2003). Integriertes Management von Wertschöpfungsnetzwerken. In N. Bach, W. Buchholz \& B. Eichler (Eds.), Geschäftsmodelle für Wertschöpfungsnetzwerke (pp. 145-178). Wiesbaden: Gabler Verlag.

Breuer, H., \& Lüdeke-Freund, F. (2015, May). Values-Based Innovation Framework - Innovating by What We Care About. In The Proceedings of the XXVI ISPIM Conference. www.academia.edu/24458877/ Values_Based_Innovation_Framework_Innovating_by_What_We_Care_About

Breuer, H., \& Lüdeke-Freund, F. (2017). Values-based network and business model innovation. International Journal of Innovation Management, 21(03), 1750028. doi:10.1142/S1363919617500281

Breuer, H., \& Lüdeke-Freund, F. (2019). Values-based stakeholder management: Concepts and methods. In T. Wunder (Ed.), Rethinking Strategic Management: Sustainable Strategizing for Positive Impact (pp. 217239). Cham: Springer.

Creswell, J. W. (2014). A Concise Introduction to Mixed Methods Research. Los Angeles, CA: SAGE publications.

Doleski, O. D. (2015). Integrated Business Model - Applying the St. Gallen Management Concept to Business Models. Wiesbaden: Springer Gabler.

Dougherty, D. (2002). Building Grounded Theory: Some Principles and Practices. Companion to Organizations (pp. 849-867). Oxford: Blackwell Publishers.

Edwards, M. G. (2010). Organizational Transformation for Sustainability: An Integral Metatheory (Vol. 2). New York, NY: Routledge.

Edwards, M. G. (2014). A metatheoretical evaluation of chaordic systems thinking. Systems Research and Behavioral Science, 31(2), 160-180. doi:10.1002/sres.2193

Erk, C. (2016). Was ist ein System?: eine Einführung in den klassischen Systembegriff. Münster: LIT Verlag.

Flick, U. (Ed.). (2013). The SAGE Handbook of Qualitative Data Analysis. Los Angeles, CA: Sage.

Geissler, C., \& Krys, C. (2013). The challenges of strategic management in the twenty-first century. In B. Schwenker \& T. Wulf (Eds.), Scenario-Based Strategic Planning (pp. 21-41). Roland Berger School of Strategy and Economics. Wiesbaden: Springer Gabler.

Gimpel, H., Graf-Drasch, V., Kammerer, A., Keller, M., \& Zheng, X. (2019). When does it pay off to integrate sustainability in the business model? - A game-theoretic analysis. Electronic Markets, 1-18. doi:10.1007/s12525-019-00361-y

Glaser, B., \& Strauss, A. (1967). The Discovery of Grounded Theory: Strategies for Qualitative Research. Mill Valley: Sociology Press.

Hermel, P., \& Ramis-Pujol, J. (2003). An evolution of excellence: Some main trends. The TQM Magazine, 15(4), 230-243. doi:10.1108/09544780310486146

Hillman, A. J., \& Keim, G. D. (2001). Shareholder value, stakeholder management, and social issues: What's the bottom line?. Strategic Management Journal, 22(2), 125-139. doi:10.1002/1097-0266 (200101)22:2\%3C125::AID-SMJ150\%3E3.0.CO;2-H

Hofmann, F. (2019). Circular business models: Business approach as driver or obstructer of sustainability transitions? Journal of Cleaner Production, 224, 361-374. doi:10.1016/j.jclepro.2019.03.115

ISO. (2020). Management System Standards (MSS). www.iso.org/management-system-standards.html 
Kämpf-Dern, A. (2009). Immobilienwirtschaftliche Managementebenen und-aufgaben: Definitionsund Leistungskatalog des Immobilienmanagements. In A. Pfnür (Ed.), Arbeitspapiere zur immobilienwirtschaftlichen Forschung und Praxis, 15. www.real-estate.bwl.tu-darmstadt.de/media/bwl9/dateien/ arbeitspapiere/arbeitspapier_15.pdf

Kämpf-Dern, A. (2010). Organisation des Immobilienmanagements als Professional Service - Performanceorientierte Konfigurationen am Beispiel des Real Estate Assetmanagements (No. 47399). Darmstadt Technical University, Department of Business Administration, Economics and Law, Institute for Business Studies (BWL). Köln: Immobilien Manager Verlag (IMV).

Kämpf-Dern, A., \& Pfnür, A. (2009). Grundkonzept des Immobilienmanagements: Ein Vorschlag zur Strukturierung immobilienwirtschaftlicher Managementaufgaben. In A. Pfnür (Ed.), Arbeitspapiere zur immobilienwirtschaftlichen Forschung und Praxis, 14. www.real-estate.bwl.tu-darmstadt.de/media/bwl9/ dateien/arbeitspapiere/arbeitspapier_14.pdf

Kämpf-Dern, A., \& Pfnür, A. (2014). Best practice, best model, best fit. Journal of Corporate Real Estate, 16(2), 97. doi:10.1108/JCRE-09-2013-0027

Kanter, R. M. (2011). Managing yourself: Zoom in, zoom out. Harvard Business Review, 89(3), 112-116. https://hbr.org/2011/03/managing-yourself-zoom-in-zoom-out

Porter, M. E. (1979). The structure within industries and companies' performance. The Review of Economics and Statistics, 214-227. https://econpapers.repec.org/RePEc:tpr:restat:v:61:y:1979:i:2:p:214-27

Porter, M. E. (1985). Competitive Advantage: Creating and Sustaining Superior Performance. New York, NY: Free Press.

Porter, M. E. (2008). The five competitive forces that shape strategy. Harvard Business Review, 86(1), 25-40. Harvard: HBR Press.

Rüegg-Stürm, J. (2002). Das neue St. Galler Management-Modell. Grundkategorien einer integrierten Managementlehre. Bern: Haupt.

Rüegg-Stürm, J., \& Grand, S. (2017). Das St. Galler Management-Modell. Bern: Haupt Verlag.

Rüegg-Stürm, J., \& Grand, S. (2019). Managing in a Complex World. The St. Gallen Management Model. Stuttgart: UTB. Kindle-Version.

Schnetzler, M. J., Sennheiser, A., \& Schönsleben, P. (2007). A decomposition-based approach for the development of a supply chain strategy. International Journal of Production Economics, 105(1), 21-42. doi:10.1016/j.ijpe.2006.02.004

Seiler, M., Cott, A. B., Torres, V., Reif, J. A., Kugler, K. G., Gammel, J. H., \& Brodbeck, F. C. (2020). Combining Values-Based and Evidence-Based Innovation Management: Impact on Innovation Culture and Idea Generation. In ISPIM Conference Proceedings (pp. 1-16). Manchester: The International Society for Professional Innovation Management (ISPIM).

SGMM Website. (2020a). Working with. www.sgmm.ch/en/about-the-model/working-productively-withthe-sgmm/

SGMM Website. (2020b). History. www.sgmm.ch/en/about-the-model/history/?noredirect=en-US

Straub, R. (2013). Why managers haven't embraced complexity. Harvard Business Review, 56(5). Harvard: HBR Press.

Strauss, A., \& Corbin, J. M. (1990). Basics of Qualitative Research: Grounded Theory Procedures and Techniques. Los Angeles et al: Sage Publications.

Ulrich, H. (1984). Management - a misunderstood societal function. In H. Ulrich \& G. J. Probst (Eds.), Self-organization and Management of Social Systems: Insights, Promises, Doubts, and Questions (pp. 80-93). Berlin: Springer.

Ulrich, H., Dyllick, T., \& Probst, G. J. (1984). Management, Schriftenreihe Unternehmung und Unternehmensführung. Bern: Paul Haupt.

Ulrich, H., \& Krieg, W. (1972). Das St. Galler Management-Modell, Bern 1972. In Das St. Galler Management-Modell: Grundlagen des Führungsmodells; ein Management-Modell für die öffentliche Hand. Bern: Haupt.

Velter, M. G. E., Bitzer, V., Bocken, N. M. P., \& Kemp, R. (2020). Sustainable business model innovation: The role of boundary work for multi-stakeholder alignment. Journal of Cleaner Production, 247, 119497. doi:10.1016/j.jclepro.2019.119497

Wieland, J. (2014). Forms of economic organization - normative strategic management. In J. Wieland (Ed,), Governance Ethics: Global Value Creation, Economic Organization and Normativity (pp. 197-213). Cham: Springer.

Witzel, A. (2000). The problem-centered interview. Forum Qualitative Sozialforschung/Forum. Qualitative Social Research, 1(1), 22. http://nbn-resolving.de/urn:nbn:de:0114-fqs0001228

Yin, R. K. (2017). Case Study Research and Applications: Design and Methods. Los Angele, CA: Sage Publications. 